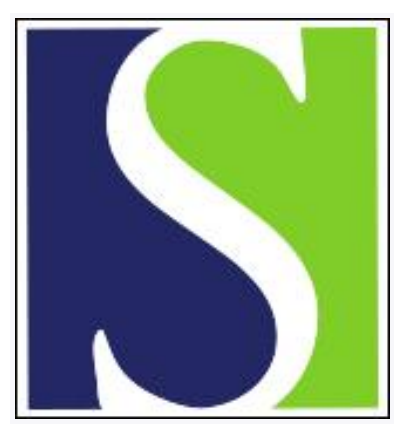

Scand J Work Environ Health 2006;32(4):328-330

https://doi.org/10.5271/sjweh.1017

Issue date: 31 Aug 2006

Sleep deprivation of working adolescents-a hidden work hazard

by Teixeira LR, Fischer FM, Lowden A

Affiliation: Department of Environmental Health, School of Public Health, University of São Paulo, Avenida Dr.Arnaldo 715, SP 01246-904, Brazil. Irt@usp.br

Key terms: child labor; educational program; opinion; sleep deprivation; sleep hygiene; teenage worker; work hazard; workhours; working adolescent

This article in PubMed: www.ncbi.nlm.nih.gov/pubmed/16932831

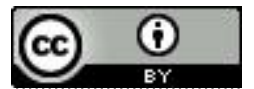




\title{
Sleep deprivation of working adolescents-a hidden work hazard
}

\author{
by Liliane R Teixeira, MPH, ${ }^{1}$ Frida M Fischer, PhD, ${ }^{1}$ Arne Lowden PhD ${ }^{2}$
}

\begin{abstract}
Teixeira LR, Fischer FM, Lowden A. Sleep deprivation of working adolescents-a hidden work hazard. Scand J Work Environ Health 2006;32(4):328-330.

This manuscript discusses the sleep deprivation of adolescents and young workers and its impact on their work and learning. Several studies have shown that working adolescents wake up earlier, have a shorter nocturnal sleep duration and a higher level of sleepiness during wake time during the week than nonworking students do. These studies indicate that working students may have their learning ability negatively affected by being tired and sleepy. Therefore, on the basis of these results, the authors recommend that educational programs geared to sleep hygiene should be one of the priorities of the curriculum. At the same time, the workhours of teenagers should be shortened in order to allow them to work and study during daytime and to have enough time at night for leisure and rest. These recommendations would improve the quality of life of the population that already is or will soon be participating in the job market.
\end{abstract}

Key terms child labor; educational program; sleep hygiene; teenage worker; workhours.

Adolescents must wake up very early in the day, and this early rising contributes to their chronic sleep deprivation during weekdays. Working adolescents might be at greater risk since their dual assignments further limit time for sleep. This limit may cause poor attentiveness during classes and the feeling of fatigue and thereby hinder the performance of working high school students both while at school and during free time. The studies conducted by Carskadon et al (1) and other researchers not only show that adolescents are sleep deprived due to the dual duty of school attendance and work, but that they are also at an elevated risk of accidents while at work as a result of being tired and sleepy.

According to surveys carried out by the International Labour Organization (ILO), at least 120 million children between 5 to 14 years of age work full-time in developing countries, where child labor predominates. An average of $25 \%$ of children are engaged in some form of economic activity. Asia has about $61 \%$ working children, whereas Africa has $32 \%$ and Latin America has $7 \%$. In industrialized countries, although child labor is less common, the phenomenon is growing again in several places, particularly in eastern European countries in transition to a market economy (2). In Brazil, where several research projects have addressed the issue, ap- proximately 5 million Brazilian teens below 18 years of age have a job. This high employment rate for teens is due to multiple factors, including economic problems, government incentives, and family and social values.

Several Latin American studies aiming to evaluate work conditions and health outcomes among working adolescents have earlier been published (3-8). Results from these studies show that adolescents who work and attend evening classes wake up earlier and have a shorter nocturnal sleep duration and shorter total sleep duration during the week than nonworking students. When time spent in daily activities was studied, it was found that time traveling to school and work affected sleep duration, but it also diminished the time students remained in school and the time in extracurricular activities (such as, for example, language courses, computer courses, and physical activities). During the workweek, adolescents have been shown to have greater difficulty waking up in the morning and to have worse sleep quality. On weekends workers initiate sleep earlier, have shorter sleep duration, and wake up by themselves easier than nonworking adolescents (5). Napping during daytime can be geared by cultural factors but can also be part of a strategy to reduce sleep debts and prevent excessive sleepiness among adolescents, as observed by

1 School of Public Health, Department of Environmental Health, University of São Paulo, Brazil.

2 Karolinska Institutet, Institute of Psychosocial Medicine, Stockholm, Sweden.

Reprint requests to: LR Teixeira, Department of Environmental Health, School of Public Health, University of São Paulo, Avenida Dr.Arnaldo 715, SP 01246-904, Brazil. [E-mail: lrt@usp.br] 
Lawrence \& Shurley (4) and Teixeira et al (5-6) studying Brazilian, Guatemalan, and Mexican working students.

It is obvious that, to ensure that sleepy or fatigued students remain engaged and motivated, teaching techniques employed in the classroom would have to be highly rewarding and stimulating. But school tasks that are complex in nature and require simultaneous abstract thinking, creativity, integration, and planning might be impervious to compensatory motivational strategies. These are tasks that might be primarily influenced by sleep deprivation (9). In schools, however, the opposite situation is often found in reality, a monotonous and sleep-inducing environment that is an obstacle for learning. Our own data indicate that working students have significantly high levels of sleepiness during wake time and at school (10). In experimentally restricted sleep studies high-level cognitive functions have consistently been impaired by sleepiness induced by sleep deprivation in adolescents, while lower-order functions show less consistency (11). However, restricted sleep, at least for children, seems to have a rapid negative effect on academic functioning according to teacher ratings (12).

According to Mitru et al (13), educational programs geared to sleep hygiene and the consequences of sleep deprivation, as well as diurnal sleepiness, should be one of the priorities of curricular programs, so as to encourage children and adolescents to gain knowledge of sleep hygiene, as the satisfaction of sleep needs is crucial for adequate performance in school. Therefore, it would be necessary for the results of scientific studies in the areas of chronobiology and sleep to be disseminated among children and adolescents. They would then begin to understand that sleepiness and fatigue may lead to emotional problems and impair school performance. After assimilating this knowledge, educators and families should encourage children and adolescents to carry out adequate sleep hygiene. Today, there are several courses on sleep medicine that could be attended by educators interested in the area, mainly science and biology teachers. In addition, the impact of sleep on the learning and sleep behavior of children and adolescents might become topics for discussion during meetings between parents and teachers.

The correlation existing between work, school, sleep deprivation, and daytime sleepiness is an issue that should be addressed by authorities, nongovernmental agencies, and the private sector. The government and the private sector might offer adolescents part-time jobs, as such an approach would reduce sleep deficit and promote learning. Students would have the opportunity to be trained and learn a profession and, at the same time, carry out educational activities. Under such a regime, the evening period could be dedicated to leisure and rest, and the number of job positions available in the mar- ketplace would be increased, adult unemployment would be reduced, and thus qualified professionals would be trained who could break loose from poverty.

According to the International Labour Organization Minimum Age Convention (no 138), of 1973, article 3 (14), "the minimum age for admission to any type of employment or work which is by its nature or the circumstances in which it is carried out is likely to jeopardize the health, safety or morals of young persons shall not be less than 18 years". The same Convention specifies that "... employment or work as from the age of 16 years may be authorized if the worker is fully protected and has received adequate specific instruction or vocational training in the relevant branch of activity."

However, nothing is said about the risk factors that can affect the sleep of children and adolescents who work. The sleep debt aggravated by the double journey of working teens has only recently been acknowledged by health and educational authorities. For example, not until 1997 was sleep debts due to work activities discussed and regarded as a work-related risk factor (15).

In view of the results presented in association with the slow process for eradicating children's work, coupled with the lack of protection for working, attention should be directed towards adolescents and the negative effects of sleep debts and sleepiness. It should help improve the quality of life of the population that is already, or will soon be, participating in the job market. As millions of young workers enter the labor force each year, sleep issues should be addressed forcefully by researchers, educators, and government representatives. Such action would further the reduction of sleepiness during classes and work and the prevention of work injuries and other negative consequences of lack of sleep. Quoting Carskadon (1): "As long as the common perception that adolescents 'need' less sleep, as long as teenagers remain ignorant of the principles of proper sleep/wake function, as long as there is a failure to understand and acknowledge the risks of excessive sleepiness, so long will a large number of youngsters be needlessly vulnerable to tragic accidents [p 326]".

\section{References}

1. Carskadon MA. Adolescent sleepiness: increased risk in a high-risk population. Alcohol Drugs Driving. 1991;5:317-28.

2. Forastieri V. Children at work: health and safety risks. Geneva: International Labour Office (ILO); 1997. ILO Child Labour Collection.

3. Fischer FM, Oliveira DC, Teixeira LR, Teixeira MCTV, Amaral MA. Effects of work on the health of adolescents. Ciênc Saúde Coletiva. 2003;8:973-84.

4. Lawrence B, Shurley JT. Comparison of sleep habits of American and Guatemalan students. Sleep Res. 1972;1:95.

5. Teixeira LR, Fischer FM, Nagai R, Turte SL. Sleep patterns of day-working, evening high-schooled adolescents of São Paulo, Brazil. Chronobiol Int. 2004;21:239-52.

Scand J Work Environ Health 2006, vol 32, no 4 
6. Teixeira LR, Fischer FM, Nagai R, Turte SL. Teen at work: the burden of a double shift on daily activities. Chronobiology Int. 2004;21:845-58.

7. Valencia-Flores M, Castaño VA, Campos RM, Rosenthal L, Resendiz M, Vergara P, et al. The siesta culture concept is not supported by the sleep habits of urban Mexican students. J Sleep Res. 1998;7:21-9.

8. Vinha D, Cavalcante JA, Andrade MMM. Sleep wake patterns of student workers and non-workers. Biol Rhythm Res. 2002;33:417-26.

9. Dahl RE. Consequences of insufficient sleep for adolescents: links between sleep and emotional regulation. Phi Delta Kappan. 1999;80:354-59.

10. Teixeira LR, Fischer FM, Nagai R, Souza LC, Turte SL, Repullo-Jr R, et al. Patterns of sleepiness among high schoolers who work and don't work. Shiftwork Int Newsl 2005; 22:148.

11. Fallone G, Owens JA, Deane J. Sleepiness in children and adolescents: clinical implications. Sleep Med Rev.
2002;6:287-306.

12. Fallone G, Acebo C, Seifer R, Carskadon MA. Experimental restriction of sleep opportunity in children: effects on teacher ratings. Sleep 2005;28:1498-9.

13. Mitru G, Millrood DL, Mateika JH. The impact of sleep on learning and behavior in adolescents. Teach Coll Rec. 2002;104:704-26.

14. International Labour Organization (ILO). Minimum age convention, convention 138, June 26 1973. Geneva: International Labour Office; 1973. Cited 05 May 2006. Available at: www.ilo.org/ilolex/english/convdisp1.htm

15. National Institute for Occupational Safety and Health (NIOSH). Child labor research needs: recommendations from National Institute for Occupational Safety and Health child labor working team. Cincinnati: NIOSH; 1997. DHHS-NIOSH publication no 97-143.

Received for publication: 09 May 2006 